\title{
Chapter 10 \\ Digital Tools in Dutch Mathematics \\ Education: A Dialectic Relationship
}

\author{
Paul Drijvers
}

\begin{abstract}
Nowadays, digital tools for mathematics education are sophisticated and widely available. These tools offer important opportunities, but also come with constraints. Some tools are hard to tailor by teachers, educational designers and researchers; their functionality has to be taken for granted. Other tools offer many possible educational applications, which require didactical choices. In both cases, one may experience a tension between a teacher's didactical goals and the tool's affordances. From the perspective of Realistic Mathematics Education (RME), this challenge concerns both guided reinvention and didactical phenomenology. In this chapter, this dialectic relationship will be addressed through the description of two particular cases of using digital tools in Dutch mathematics education: the introduction of the graphing calculator (GC), and the evolution of the online Digital Mathematics Environment (DME). From these two case descriptions, my conclusion is that students need to develop new techniques for using digital tools; techniques that interact with conceptual understanding. For teachers, it is important to be able to tailor the digital tool to their didactical intentions. From the perspective of RME, I conclude that its match with using digital technology is not self-evident. Guided reinvention may be challenged by the rigid character of the tools, and the phenomena that form the point of departure of the learning of mathematics may change in a technology-rich classroom.
\end{abstract}

\subsection{Introduction}

Since the origin of mankind, people have developed and used tools to ease their work and to carry out tasks. In the case of mathematical tasks, tools such as the abacus, the ruler and the compass have been used for centuries. More recent is the development of a fascinating category of tools, namely digital tools. This new generation of tools includes software for algebra and calculus (e.g., computer algebra systems or CAS),

\section{P. Drijvers $(\varangle)$}

Freudenthal Institute, Utrecht University, Utrecht, The Netherlands

e-mail: p.drijvers@uu.nl 
for 2D and 3D geometry (dynamic geometry systems or DSG), and for statistics (e.g., the Dutch software VuStat, see Van Streun \& Van de Giessen, 2007). Such powerful tools, in which an impressive amount of mathematical expertise is incorporated, may not only be used for 'getting the mathematical job' done, but may also affect mathematics teaching and learning. In addition, dedicated tools such as applets have been designed for specific educational purposes. These educational roles are central in this chapter.

Among mathematicians and mathematics educators, mathematics is considered as more than a set of algorithms which can be applied to solve routine problems. No matter how powerful these standard solution procedures are, and how much of human intelligence was needed to develop them, doing mathematics and, as a consequence learning mathematics, also encompasses working on problems that are new to the person involved, and requires creative problem solving and the development of new methods and knowledge. From this perspective, much attention has been paid to theories on bottom-up learning, (socio-) constructivism, discovery learning, inquirybased learning. Students should be given ample opportunity to explore, to investigate, to conjecture, and to prove. In this way, they are expected to develop meaningful mathematical insights, to (re)construct their mathematical knowledge and to acquire general skills that go beyond the specific task at stake. In the theory of Realistic Mathematics Education (RME), which is wide-spread in the Netherlands, this idea is captured in the notion of guided reinvention (Freudenthal, 1973; Van den HeuvelPanhuizen \& Drijvers, 2014). According to this principle, students should be given the opportunity to experience a process similar to that by which a given mathematical topic was invented. While doing so, students in the meantime need guidance from the teacher. A second RME concept, didactical phenomenology (Van den HeuvelPanhuizen, 2014), highlights the relation between the mathematical thought object and the phenomenon from which it emerges. In particular, it addresses the question how mathematical objects can help in organising and structuring real phenomena. The challenge for the designer, of course, is to find such meaningful phenomena that beg to be organised and structured by the targeted mathematical knowledge.

Some decades ago when digital tools for mathematics education became more widespread and increasingly powerful, mathematics educators and researchers both in the Netherlands and worldwide expected that this might provide levers to change mathematics education in the direction of the aforementioned higher-order goals, rather than focusing on the acquisition of basic paper-and-pen techniques. If digital tools would enable students to easily and quickly investigate different situations, to engage in experimentation without time-consuming work by hand, to outsource the basic techniques to digital tools, would this not offer excellent opportunities for the envisaged bottom-up and meaningful learning? Some optimism seemed appropriate.

In the educational reality of students, teachers, classrooms and schools, however, the use of digital tools for higher-order learning goals turned out to be more complex than foreseen. In addition to the sometimes problematic infrastructural demands that the use of digital tools puts on every day teaching, it became clear that each digital tool for mathematics education does not only offer opportunities, but also comes with constraints, which may be the result of either technological limitations 
or design choices. The flexibility of digital tools, and the ways in which teachers can customise them for their specific purposes, is often limited. As a consequence, their use for developing higher-order skills, which seems the most subtle, is less popular than for practicing basic skills. Overall, research results on the measurable improvement of learning are only modest (Drijvers, 2016).

As a result, there is a somewhat dialectic relationship between the higher-order goals of mathematics education, as highlighted in RME theory among others, and the opportunities and constraints digital tools offer. Can we manage to use such tools for learning goals that go beyond basic skills, or do they tend to push us back into an algorithmic approach of mathematics? How can digital tools be used for bottom-up, meaningful and realistic mathematics education? How can we optimise the design of digital tools on the one hand, and the didactical design of ways to use them in teaching on the other? In short, how can we deal with the tension between sometimes rigid digital tools and flexible teaching? This is the central issue in this chapter. To deal with this issue, I will, after a brief historical flash-back, discuss two particular cases of using digital tools in Dutch mathematics education: the case of the handheld graphing calculator (GC), and that of the Digital Mathematics Environment (DME).

\subsection{A Brief Flash-Back}

Over the past 45 years, the world-wide development of digital tools for mathematics education and their use in practice has drastically evolved, both with respect to the type of tools and the type of use. After some early applications of Computer Assisted Instruction for mathematics, in the 1970s there was a major focus on programming in Logo and BASIC, for example to make the 'turtle' move in a specific way (Drijvers, Kieran, \& Mariotti, 2010). In his book Mindstorms, Papert made a plea for programming in so-called micro worlds, claiming that " $[\mathrm{t}]$ he computer presence has catalysed the emergence of ideas" (Papert, 1980, p. 186). Programming was considered a means for enhancing students' mathematical problem-solving abilities. The availability of personal computers in the 1980s not only made programming activities more feasible in practice, but also led to the development and dissemination of dedicated software for mathematics (such as computer algebra systems), and for mathematics education (dynamic geometry systems or dedicated software, see Doorman \& Van der Kooij, 1992). General tools, such as spreadsheet software, were also used in mathematics lessons (Sutherland \& Rojano, 1993).

By the end of the 1990s, handheld technology such as GCs became widespread. The advantage of these digital tools was not only that the use of the technology no longer depended on the classroom infrastructure, but also that the initiative to use this personal device lay primarily with the students: even if guidance from the teacher was needed, in the end it was the student who decided when to use the technology, and for what purpose. The handheld format also raised the question of the use of digital tools in assessment and examinations. 
As Internet speed improved, after 2000 the use of small, dedicated applets in mathematics teaching became more popular. Online educational use gradually replaced work with locally installed software. In addition, digital tools allowed for communication, exchange and collaboration between students, and between students and teachers. Video channels offering mathematical instruction became popular, leading to the 'flipping the classroom' paradigm. Online courses started to attract huge numbers of participants.

Nowadays, we see a myriad of digital tools used worldwide, ranging from desktop PCs to laptops, tablets and smartphones. Students bring their own devices, and broadband internet is the gateway to different types of applications. Using digital tools in the mathematics classroom has become natural, and less prominent than it used to be in dedicated 'technology lessons' in the past.

Developments in the Netherlands took place along similar lines. In the 1970s, programming was popular, including work with flow charts and scratch cards to execute programs written in educational programming languages such as Algol and Ecol (Vonk \& Doorman, 2000). In the 1980s, the personal computer started to make life easier. However, schools used a diversity of brands of computers and different operating systems. It was only after a national project called 'NIVO' brought some uniformity, that using ICT in education became more common. In the 1990s, ICT also became integrated in subject curricula. Schools were equipped with computer labs. After 1999, GCs became mandatory for pre-university education for students aged 15-18. With the advent of broadband internet, applets were being used more and more, in particular those from the DME developed at Utrecht University. Over the last decade, classrooms were equipped with interactive whiteboards, and wifi in school allows students to access the internet through their own devices. The Geogebra software is quite popular, and students make more and more use of laptops and tablets, in some schools not just in addition to textbooks, but as a replacement. The question, however, is how the type of use and its didactical and theoretical backgrounds have developed over this period.

\subsection{The Case of Handheld Graphing Calculators}

To investigate how the dialectic relationship between the goals of mathematics education and the opportunities and constraints of digital tools developed over time in the Netherlands, I now describe the case of handheld GCs. I will confront the initial expectations with the developing practice and also address the specific case of symbolic calculators. The case description closes with a short conclusion. 


\subsubsection{Initial Expectations}

In the mid-1990s, the GC entered the Netherlands. This happened to coincide with a curriculum reform for pre-university mathematics for students aged 15-18, which was carried out by the Freudenthal Institute, which was the cradle of the theory of RME. As a consequence, the GC was seen as a means to bypass institutional constraints and to directly equip students with a device that would support dynamic and interactive exploration and reinvention, and this approach was integrated in the curriculum reform process. More in particular, Drijvers and Doorman (1996, p. 425) claimed that

[o]bservation of the students' behaviour during the experimental lessons supports the premise that the graphics calculator can stimulate the use of realistic contexts, the exploratory and dynamic approach to mathematics, a more integrated view of mathematics, and a more flexible behaviour in problem solving.

As an example of a task that invites such an exploratory approach, students were asked to graph functions $f$ and $g$ defined by $f(x)=a \cdot 2^{x}$ and $g(x)=2^{x+c}$ for such values of $a$ and $c$ that the two graphs would coincide. The students knew that the two graphs could be derived from the standard exponential graph with base 2 through a multiplication with a factor $a$ with respect to the $x$-axis, and a horizontal translation to the left over a distance $c$ respectively. In this way, students were offered an experimentation space for the discovery of relationships such as $2^{x+c}=2^{x} \cdot 2^{c}$, $2^{c}=a$, or $\log _{2} a=c$, depending on the level and age of the students. Speaking in general, expressing functions in terms of other functions, in this example $g(x)=$ $f(x+c)$, is a powerful means to build chain functions (Kindt, 1992a, b). More examples can be found in Doorman, Drijvers and Kindt $(1994,1996)$.

If exploration using GCs is part of teaching, it should of course also be assessed. Figure 10.1 shows part of an assignment of the national examination for the schools that piloted the new curriculum in 1999. One question was to find the value of $n$ in

$$
\begin{aligned}
& x(t)=\left(1+\frac{1}{n} \sin (n t)\right) \cos (t) \\
& y(t)=\left(1+\frac{1}{n} \sin (n t)\right) \sin (t)
\end{aligned}
$$

so that the graph of $(x(t), y(t))$ is the 'curved circle'. This task can be solved through different combinations of reasoning and drawing on the GC.

As mentioned earlier, digital tools come with limitations. An obvious limitation of the early GCs was the low-resolution screen and the not very sophisticated ways to graph functions, with sometimes confusing results. Figure 10.2, for example, shows the calculator's inappropriate way to deal with the vertical asymptote of the function $f$ defined by $f(x)=\frac{x^{2}+x-1}{x-1}$. Indeed, students were unable to correctly copy this graph on paper. Such limitations may challenge the teachers' intentions of explorative, 'real' mathematics. The solution we found to this was not to avoid such 
Fig. 10.1 Exploration task in the 1999 national pilot examination

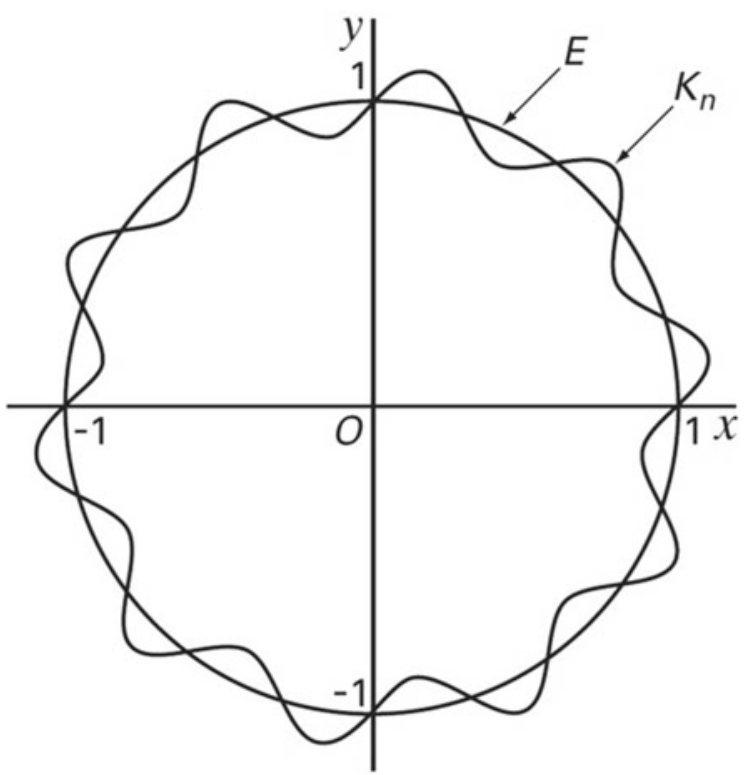

Fig. 10.2 Early GC's misleading graph

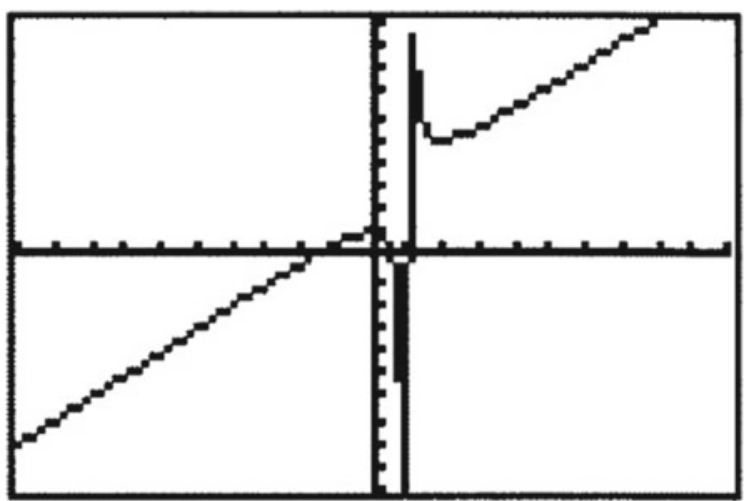

constraints, but rather to exploit them by making them explicitly subject to further investigation. In the case of the asymptotes, we invited students to try to come up with as many misleading graphs on the GC screen as they could think of, and, of course, explain why the graph was misleading and how they found it. This approach, inspired by Treffers' (1987) notion of students' own production, proved to be a fruitful one.

Of course, GCs are 'ready-made' devices that are hard to tailor to specific didactical needs. Through task design and teaching approach, we tried to exploit the tool's potential for the sake of RME. In retrospective, I may say that we were somewhat 
naive in our initial and optimistic expectations, as we probably neglected the dependency on the task and the teaching, on top of the affordances of the digital tool. From the developing practices during the following years, however, this became quite clear.

\subsubsection{Developing Practices}

Since 2001, students in the Netherlands were required to bring a GC to the national examination in mathematics for pre-university secondary education. 'Required' does not mean that nobody is allowed to take the exam without a GC; it does mean, however, that assignments may become much harder to do without a GC, and that the 'risk' of not having one, or not being able to use it appropriately, is for the candidate. The idea behind this policy was that a curriculum in which digital tools are recognised as important cannot be assessed in a technology-free manner, and the handheld personal GC would be a feasible way to include this aspect in the national written examination. Also, the national examination was expected to act as a lever to really implement a change in teaching practice in line with the opportunities described in the previous section.

Initially, the GC was also allowed for national examinations in the subjects physics, chemistry, biology and economics. However, this permission was withdrawn once the authorities became aware that students could store information (formulas, applications, texts, even pictures) on their handheld devices, which was not intended and might present candidates with unequal chances. At present (2016), mathematics is the only subject for which GC use is allowed during national examinations.

How did the national examinations change since students have had a GC at their disposal? Different countries have shown different policies to deal with technology in central examinations (Drijvers, 2009). Compared to other countries, initially Dutch policy was relatively far-reaching: the use of the GC was not only allowed, but also indispensable in some assignments, and its appropriate use was credited in some of the tasks. However, some trends need to be mentioned. First, assignments in which the GC plays an essential role in visualising or exploring a mathematical situation, such as the task from the pilot examination in 1999 shown in Fig. 10.1, are quasi non-existing. Apparently, the board that sets the examination assignments considered such tasks as too much depending on GC skills, and to a lesser extent on the mathematical insights to be assessed. Second, the number of credit points that students may get through the use of the GC seems to be decreasing over the years. In this sense, the role of the GC in examinations became smaller over the years. This may be explained by the tendency to re-value exact paper-and-pen procedures from algebra and calculus: assignments nowadays contain phrases such as "Calculate the exact value..." which require algebraic or analytic by-hand procedures, and do not credit GC generated solutions. Third and final, the number of GC techniques that are credited in examination papers became limited and standardised; in fact, students should be familiar with ways to calculate probabilities of normal and binomial distributions in statistic assignments, and with ways to calculate intersection points, zeros, 

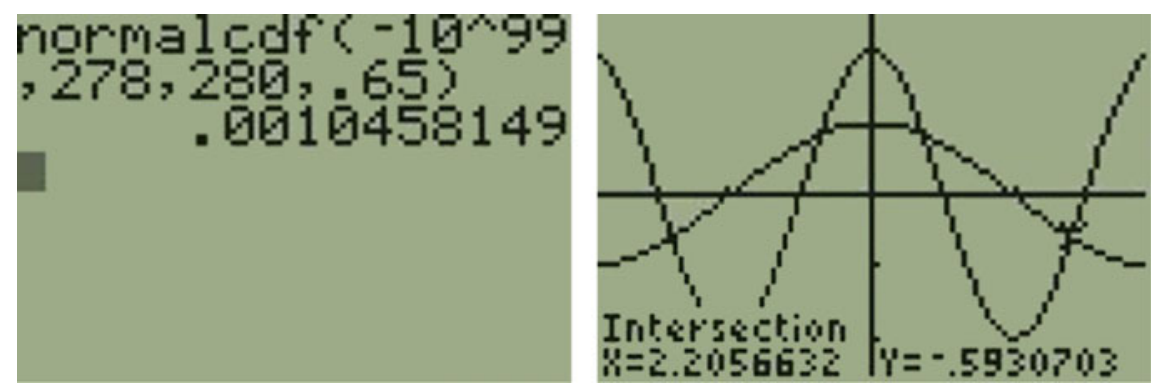

Fig. 10.3 Standard GC procedures to find intersection points and to calculate probability from Dutch 2015 mathematics examinations

maxima and minima in calculus and algebra tasks. Figure 10.3 shows an example of these two procedures, as asked for in the 2015 national examinations in mathematics in the Netherlands. The left screen shows the calculation of a probability for a normal distribution, and the right one the approximation of a solution of the equation $2 \cdot \cos (2 t)=\cos (t)$.

Since GCs became mandatory in mathematics examinations, textbook series of course also included references to these devices. Again, the type of tasks and the ways to use the $\mathrm{GC}$ were not as oriented towards exploration, visualisation and reinvention as the exemplary student materials in the curriculum development project had been. Rather, the textbooks focus on the previously mentioned GC procedures for statistics and calculus. As a consequence, teachers also make sure that their students master this small repertoire of standard techniques, rather than exploiting the didactical opportunities of the GC in their lessons.

In short, teaching and assessment practice in Dutch upper secondary mathematics education with respect to the integration of the GC did not have the effect that was hoped for. Compared to the ideas expressed earlier, the role of the GC remained limited to some specific techniques, which students also apply in easy cases. For example, students may use an intersect procedure to solve an equation like $2 x+3=7$. On the one hand, this may endanger the maintenance of paper-and-pen skills. On the other hand, this is what technology nowadays offers. The main reasons for this limited use probably lie in the developing opinion in the field of mathematics teachers, educators and mathematicians. On the one hand, innovative and technology-oriented people soon started to consider the GC as 'old school' technology, compared to more advanced devices such as tablets, laptops and smartphones. On the other hand, more conservative voices in the field expressed their concern about students' paper-andpencil techniques and stress the need to put aside the GC (and other digital tools) to make students master these basic skills. In this way, the GC became tangled between ICT-oriented and back-to-basics protagonists. 


\subsubsection{Additional Symbolics}

In the meantime, symbolic calculators (SCs), i.e., handheld devices that also offer computer algebra on top of GC features, received international attention. Many teachers, educators and researchers were fascinated by the immense mathematical and symbolic power embedded in such small, handheld devices. Still, it was unclear what the consequences of this technological development should be for secondary mathematics education.

In the Netherlands, the use of symbolic calculators in secondary education was investigated in the PhD. study by Drijvers (2003). The study shows both the potential of computer algebra in mathematics education and its constraints. As was the case for the GC, the somewhat rigid character of computer algebra environments may hinder students' expressiveness and teachers' creativity. In the case of computer algebra, the strict syntax for algebraic commands turned out to be one of the most important obstacles. Again, similar to the GC, an interesting didactical approach to deal with these constraints was to explicitly address them and to take computer algebra as an expert system which is subject to the students' investigations: How does the device get its answers? How to explain differences with what would be expected? In this way, obstacles may be turned into opportunities (Drijvers, 2002). For the case of algebraic equivalence, this approach is elaborated in more detail by Kieran and Drijvers (2006).

The SC had a limited impact on teaching practice in the Netherlands. The reasons are to a certain extent similar to those in the case of the GC: as paper-and-pencil algebraic skills are highly valued, equipping students with computer algebra does not seem the right thing to do. Therefore, SCs were banned from national examinations. Also, the limitations of computer algebra and the difficulty to use it were not in the SC's favour. The argument that symbolic calculation tools might free students from calculational drudgery and open horizons for modelling, application, investigation, and reinvention was, once more, not highly valued.

The reason to mention symbolic calculators here in spite of their limited impact is that international research on their use did lead to fruitful theoretical perspectives, which may be applied to the use of digital tools in general. A core point is the bidirectional relationship between tools and their users, in which students' thinking is on the one hand shaped by the digital tool, and on the other hand shapes the way the tool functions (Hoyles \& Noss, 2003). This is reflected in the notion of instrumental genesis, the co-emergence of techniques for using digital tools and the mathematical insights involved (Artigue, 2002; Trouche, 2004; Trouche \& Drijvers, 2010).

\subsubsection{Conclusions on the Graphing Calculator Case}

The case of the introduction of the GC in Dutch mathematics education first shows the initial enthusiasm, reflected in the design and use of innovative tasks that exploit 
the technology's potential for exploration and reinvention. Next, I describe the implementation in both examination and teaching practice, which is to a lesser extent driven by a guided-reinvention view on mathematics, and comes down to equipping students with a limited repertoire of standard techniques for using the GC; techniques which are of course of practical value. This development may be caused by the limited and rigid character of the GC, in combination with public opinion in the Netherlands shifting towards paper-and-pencil basic skills.

Even if the didactical policy of turning constraints into opportunities was in some cases a fruitful one, it became clear that the digital tool's limitations may hinder the creative design of open and engaging tasks. An important criterion for digital tools in mathematics education, therefore, is their expressive power for students, so that they enable students to explore and express mathematical ideas in accessible and natural ways.

\subsection{The Case of the Digital Mathematics Environment}

As a second case reflecting the dialectic relationship between the goals of mathematics education and the opportunities and constraints of digital tools, I now consider the development of the DME. The DME is an online environment for mathematics activities developed by Utrecht University's Freudenthal Institute. I will first briefly sketch the DME's technological development. Next, design choices will be discussed, as well as the role of the teacher, which was the topic of adjacent research. The case description closes with a conclusion.

\subsubsection{Technological Development}

In the late 1990s, the DME (https://www.numworx.nl/en/log-in/) started as an initiative by Peter Boon, who was a mathematics teacher at the time, and an expert in programming. His initial idea was to design Java applets that were available online and that would facilitate students' exploration of mathematical objects and concepts. In collaboration with colleagues at the Freudenthal Institute, applets were designed for several topics, such as 3D geometry (Kindt \& Boon, 2001), algebra (Boon, 2004), and on the intuitive notion of functions as chains of operations (Boon \& Drijvers, 2006). As these applets were field-tested and soon became popular in schools, and as their number was growing over the years, a content management system was needed to organise the content collection, as well as a player to deliver this content. In addition to programming applets, the architecture of the environment as a whole became a focus.

One of the powerful features of digital tools in general is the option to keep track of student progress, either to inform students and teachers, or to provide automated feedback, or to score student work. For this reason, a learning management system 
was embedded in the DME, which on the one hand provides students with feedback on their work and on the other hand offers overviews of students' progress to their teachers.

Initially, a core activity while designing the DME was the programming of applets. Gradually, the difference between programming on the one hand, and designing the tasks and activities for students that come with the available applications on the other hand, grew bigger. For this reason, the DME authoring environment was developed. It allows educational designers, such as teachers, educators or text book authors, to design activity sequences for students without engaging in programming the applets that form the basis of these activities. In the authoring environment, authors adapt existing online modules or design new ones, using existing applets and basic tools such as graphing and equation editing facilities as building blocks. Knowledge of the underlying programming language is not required; rather, an intuitive and mathematical interface makes the digital design accessible to a wide audience (Fig. 10.4).

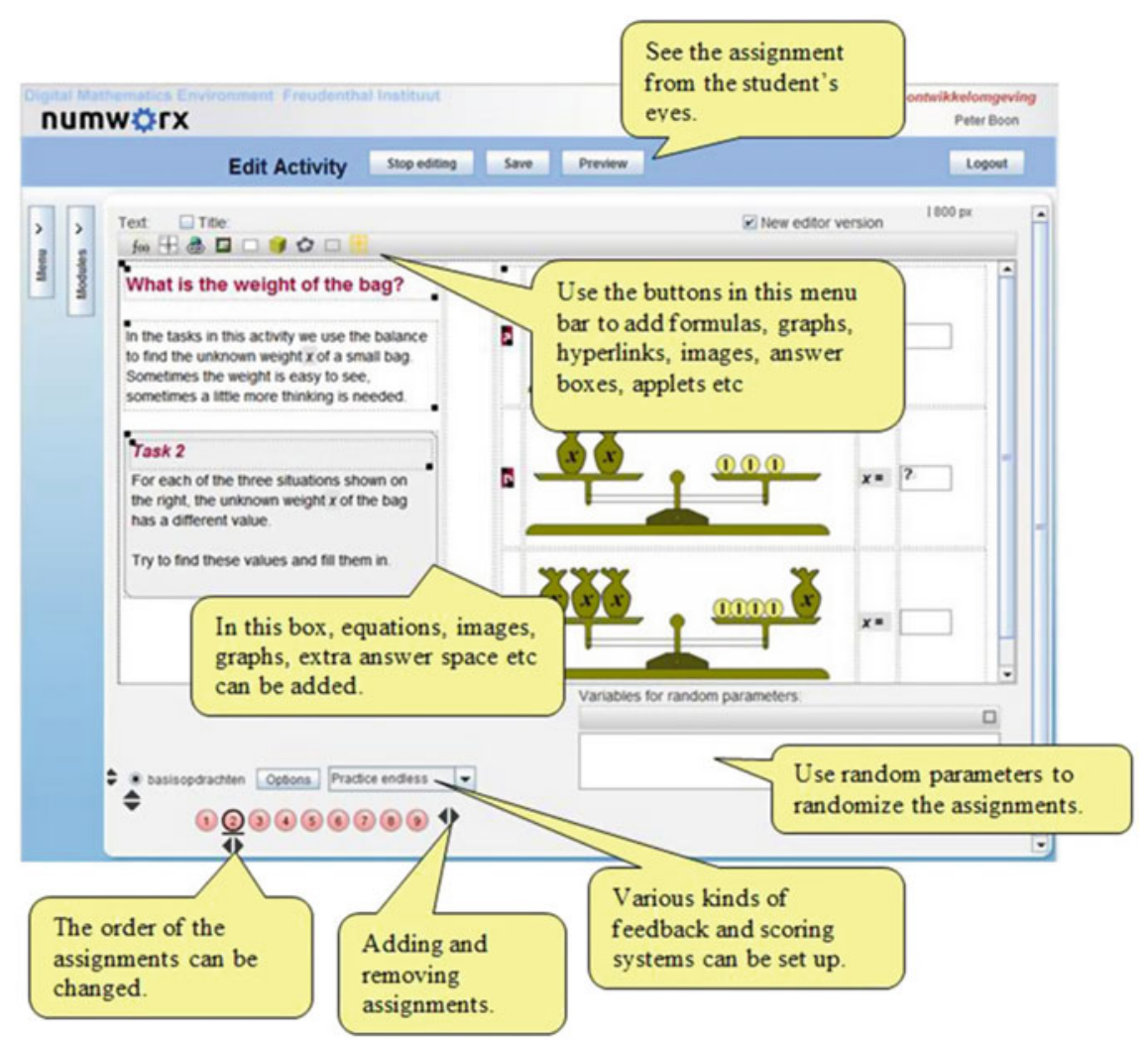

Fig. 10.4 The DME authoring environment 
Nowadays, the DME includes a player, a content management system, a learning management system and an authoring environment. It has moved to html5, provides advanced features for assessment and adaptivity, has a computer algebra engine available, and hand writing recognition.

\subsubsection{Design Choices}

Even if the DME's design did not follow a fixed road map scheduled in advance, its development has always been guided by a set of (sometimes implicit) design principles. Boon (2009) describes how his points of departure were to make the software flexible and customisable, and to always keep in mind other possible educational applications of a designed piece of software. As a consequence, the DME had a modular character, in which the basic building blocks, the applets, can be re-used and adapted to the specific didactical goals at stake. In this way, the DME became a rich and flexible environment for mathematical activity.

As the DME was developed within Utrecht University's Freudenthal Institute, it is not surprising that the theoretical foundation of its design is rooted in the theory of RME. This theory is reflected in DME characteristics in several ways. With respect to students, many DME applets and activities offer them room for expressing their mathematical ideas, exploring mathematical situations, and reinventing mathematical properties. Also, according to the notion of didactical phenomenology, it is central to engage students in situations that invite the development of mathematical thinking in a natural and mathematically sound way. And finally, students should be productive in the DME activities rather than reproductive. As a consequence of the dedicated design of applets and student activity, instrumental genesis is expected to take place in a more natural way than in the case of more general and less flexible tools, such as the GC.

With respect to teachers, the DME also has some features that can be related to the RME theory. Due to its flexible character, and the availability of the authoring environment and the applet collection as building blocks, the DME offers teachers the opportunity to engage in design, to be productive themselves, and to acquire ownership of their teaching and teaching materials. This ownership is not self-evident in the Netherlands, where teachers usually rely strongly on the regular mathematics textbook series, rather than designing their own materials and lessons. As such, the DME is a less ready-made digital tool than GCs or computer algebra environments, for example.

As the DME is used by a wide variety of users, the RME points of departure do not guarantee educational products (i.e., online modules) that reflect the RME theory. In fact, from the early years on, some applets on practicing solving linear equations became popular, whereas the RME approach in these applications is not very prominent. If the DME starts to 'live' in the mathematics education community, full control will of course be out of the hands of the software architects. 


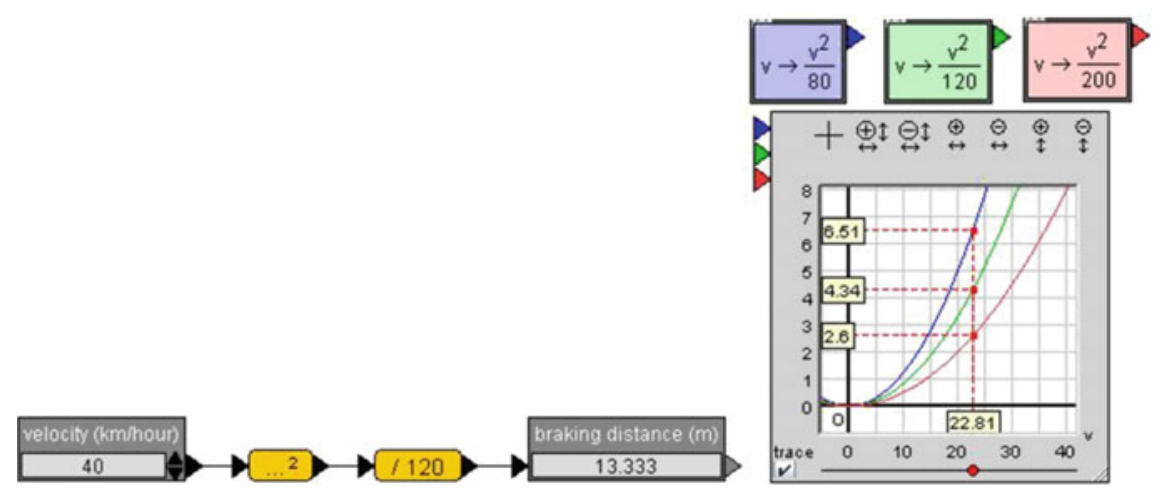

Fig. 10.5 Stepwise arrow chain (left) and collapsed arrow chains (right), from (Drijvers, Boon, Doorman, Bokhove, \& Tacoma, 2013)

The development of the DME did not only include technological design, but was part of an iterative process of designing, field-testing, and improving, that is typical for educational design. The development of the DME has always had a strong link to research projects, which in most cases had a cyclic design-based research character. Studies that rely on DME affordances, but also informed its further development, are manifold (e.g., Jupri, Drijvers, \& Van den Heuvel-Panhuizen, 2016). Let us briefly consider some examples.

As an example of a study that both made use of the DME and informs its development, Doorman, Drijvers, Gravemeijer, Boon, and Reed (2012) describe how a teaching sequence on functional thinking using an applet called "Algebra Arrows" led students to develop a structural view on function. Based on the notion of emergent modelling (Gravemeijer, 1999), the teaching sequence integrated both paper-andpen and digital work. As an illustration, Fig. 10.5 shows how student may 'collapse' chains of operations into functional objects.

As a second example, Bokhove and Drijvers (2012a, b) investigated feedback design in DME modules for 17- and 18-year-old students on equation solving. Different types of feedback and feedback conditions were compared (see Fig. 10.6). As an overall conclusion, feedback timing and fading seemed crucial for its effects. In an effect study using multilevel models, the feedback-rich intervention indeed turned out to be effective (Bokhove \& Drijvers, 2012b). In another study, however, on 13and 14-year-old students solving linear and quadratic equations in the DME, the intervention was not successful (Drijvers, Doorman, Kirschner, Hoogveld, \& Boon, 2014). Apparently, the success of such interventions is not straightforward. The role of the teacher might be a crucial factor here, which is why I consider it in the next section.

In short, the design of the DME is strongly influenced by RME principles and by the interaction between design and adjacent educational research. It is these factors that helped the DME to develop into a rich and flexible environment for mathematics 


\begin{tabular}{|l|l|l|l|}
\hline Step & Student & & Feedback \\
\hline 0 & $\left(x^{2}+x-6\right)(7 x-6)=\left(x^{2}+x-6\right)(3 x+12)$ & & Hint: $A B=A C=>A=0$ or $B=C$ \\
\hline 1 & $x^{2}+x-6=0$ or $7 x-7=3 x-12$ & $\mathrm{X}$ & \\
\hline 2 & $x^{2}+x-6=0$ or $7 x-6=3 x-12$ & $\checkmark$ & You are rewriting correctly \\
\hline 3 & $x=\frac{-1-\sqrt{25}}{2}$ or $x=\frac{-1+\sqrt{25}}{2}$ or $x=4 \frac{1}{2}$ & & This is not quite the exact format \\
\hline 4 & $x=-3$ or $x=2$ or $x=4 \frac{1}{2}$ & Y & $\begin{array}{l}\text { You have solved the equation } \\
\text { correctly }\end{array}$ \\
\hline
\end{tabular}

Fig. 10.6 Stepwise feedback including hints (Bokhove \& Drijvers, 2012a)

education in the way it did, and to reduce the tension between rigid digital tools on the one hand, and flexible didactical approaches on the other.

\subsubsection{Role for the Teacher}

In addition to the different levels of design in the DME, including programming applets and global environment features, and designing student activities, a third level is of course crucial: the use of the DME in teaching. This includes (1) preparing lessons, in some cases through the adaptation of existing activities to the teaching purpose and target group involved, (2) delivering lessons according to these plans, and (3) dealing with unexpected events while teaching, either from the digital technology or from student behaviour. As for other digital tools, the exploitation of the potential of the DME is not straightforward to teachers. Therefore, research has been carried out at the Freudenthal Institute to investigate the professional development needed by teachers to fully benefit from the opportunities the DME offers.

As a theoretical lens in this research, the notion of instrumental orchestration (Trouche, 2004) is used. An instrumental orchestration is defined as "the teacher's intentional and systematic organisation and use of the various artefacts available in a-in this case computerised-learning environment in a given mathematical task situation, in order to guide students' instrumental genesis" (Drijvers et al., 2010, p. 214-215). Three levels are distinguished: the didactical configuration, the exploitation mode and the didactical performance. A study on three teachers using the "Algebra Arrows" applet shows that teachers have their preferences for specific types of orchestrations, and that these preferences relate to their views on mathematics education (Drijvers et al., 2010; Drijvers, Godino, Font, \& Trouche, 2013). A study with twelve mid-adopting teachers using different applets within the DME documents the extension of the teachers' repertoire of orchestrations as a characteristic of their professional development (Drijvers, Tacoma, Besamusca, Doorman, \& Boon, 2013). 
From the RME perspective of guided reinvention, the DME is challenging. On the one hand, many DME activities are designed to provide means for exploration and reinvention to students. On the other hand, we notice a tendency in teachers, who often are novices in teaching with digital tools and are themselves in the process of instrumental genesis, to step back as soon as students interact with digital tools, and to fall back on 'old' teaching strategies such as teacher-driven explanations. As ICT may be a new and complicating element in the didactical configuration, this may hinder the teachers' flexible attitude that is needed to appropriately support the students' process of reinvention. To be confident, to identify opportunities and constraints of the digital activities, and to adapt teaching experience and skills to the technology-rich classroom, is a challenge for teachers. Professional development can play an important role in helping teachers to also engage in RME-based teaching in a digital setting.

\subsubsection{Conclusion on the Digital Mathematics Environment Case}

The case of the DME shows that software design can be more closely related to a theoretical view on the teaching and learning of mathematics than is the case for the GC. Also, the iterative design is underpinned by research, and the interplay between design and research is known to be a powerful one (e.g., see Bakker \& Van Eerde, 2015). The fact that educational designers, software designers, teachers and researchers work together guarantees close-to-practice solutions that are also theoretically grounded. This way of working may reduce the tension between a teacher's didactical goals and the software's affordances. As a result, much of the DME content offers room for students to explore and to construct, to be productive, and as such may facilitate a guided reinvention approach to mathematics education.

To bridge the gap between task design and software design, that is so manifest in the case of the GC, the DME authoring environment empowers teachers to adapt tasks and applications, and to design new ones. This improves the teachers' ownership of their teaching materials, which we consider a good thing. In the meantime, we should acknowledge that it is demanding for a mathematics teacher to (re-)design materials in the DME, not only for reasons of time, but also because of the didactical insights and creativity needed. It is here that the need for professional development comes into play. Professional development activities complement the collaboration between designers, teachers and educators mentioned above.

What we do learn from the DME case, finally, is that software for mathematics education should be designed for different educational applications, and should be flexible and customisable. As Boon (2009, p. 10) phrases it, we should design software as "a collection of reusable components and packages". In this way, activities addressing new phenomena may be easily created based on existing activities. 


\subsection{Conclusion}

In the introduction of this chapter, I mentioned the dialectic relationship between the higher-order goals of mathematics education, and the opportunities and constraints digital tools offer. Indeed, as Hoyles and Noss write: "Tools matter: they stand between the user and the phenomenon to be modelled, and shape activity structures" (Hoyles \& Noss, 2003, p. 341). The two cases described in this chapter help us to further specify this dialectic relationship for students and for teachers.

For students, using digital tools for mathematics in addition to paper and pen may lead to new opportunities and constraints. New techniques for using the tool for a type of task need to be developed, and each technique affects the concept image as it emerges in the students' minds. The interaction between technical mastery and conceptual understanding is a subtle one. Whereas a mismatch between the two may hinder learning, a natural fit between technique and the mathematics at stake may foster mathematical understanding. Whereas the constraints, such as syntactical demands, may frustrate students, room for exploration may foster engagement in rich explorative and productive activities.

The challenge for teachers, therefore, is to exploit the opportunities and to deal with the constraints. Teachers may experience some tension between their didactical aims and goals, and what can really be done in the digital environment. Two levels of educational design come into play: the design of tasks and student activities on the one hand, and the customisation or design of the software on the other. In many cases, the latter type of design is too time-consuming or too difficult to be within the teachers' scope. Therefore, an important criterion for educational software is the option for teachers to tailor it to their didactical intensions, taking into account instrumental genesis and the subtle relationship between tool use and mathematical thinking. What counts, after all, is not the digital tool itself, but the way it is part of a didactical approach, including tasks, activities, discussions and assessment. To oversee the role of digital tools in this spectrum is not trivial for many teachers; professional development may be useful here.

From the perspective of RME, I conclude that the match between RME and using digital technology is not self-evident. With respect to guided reinvention, the integration of digital technology in mathematics teaching may initially be a complicating factor to teachers, which challenges established teaching techniques. To remain in control, teachers may react to this by focusing on traditional forms of teaching such as demonstrations and explanations. This may lead to more guidance and less room for reinvention. As a consequence, the guided reinvention approach may need extra attention when technology enters the classroom.

As for didactical phenomenology, I conclude that the phenomena may change in a technology-rich classroom. The digital environment itself may be a meaningful phenomenon to the student. The GC's limitations with respect to graphing asymptotes turned out to be an inspiring phenomenon to elicit algebraic thinking. In the meantime, using digital tools may also create some distance to the phenomena at stake. For example, drawing a circle with a physical compass does require a circular hand 
movement; in a dynamic geometry software environment, this physical connection between the hand movement and the geometrical object is less evident, as students just have to click on a centre point and a point at the radius distance. It is important that the phenomena explored in a digital environment can be presented and manipulated in a natural way, which corresponds with representations and manipulations in the physical world. Interesting ongoing research investigates how such embodied experiences can be simulated on digital devices (Abrahamson, Shayan, Bakker, \& Van der Schaaf, 2016).

Altogether, the challenge for teachers, designers, educators, and researchers is to create digital tools that are flexible and customisable, that offer room for exploration to students, and that teachers can easily adapt to their specific didactical goals. Teaching with technology should not default to traditional techniques because of the increasing complexity of the teaching environment, and attention needs to be paid to presenting phenomena in natural and meaningful ways. These are not straightforward challenges; in the meantime, progress has been made and a joint effort is needed to make the integration of digital tools in mathematics education a widespread success.

\section{References}

Abrahamson, D., Shayan, S., Bakker, A., \& Van der Schaaf, M. (2016). Eye-tracking Piaget: Capturing the emergence of attentional anchors in the coordination of proportional motor action. Human Development, 58(4-5), 218-244.

Artigue, M. (2002). Learning mathematics in a CAS environment: The genesis of a reflection about instrumentation and the dialectics between technical and conceptual work. International Journal of Computers for Mathematical Learning, 7, 245-274.

Bakker, A., \& Van Eerde, H. (2015). An introduction to design-based research with an example from statistics education. In A. Bikner-Ahsbahs, C. Knipping, \& N. Presmeg (Eds.), Doing qualitative research: Methodology and methods in mathematics education (pp. 429-466). Berlin, Germany: Springer.

Bokhove, C., \& Drijvers, P. (2012a). Effects of feedback in an online algebra intervention. Technology, Knowledge and Learning, 17(1/2), 43-59.

Bokhove, C., \& Drijvers, P. (2012b). Effects of a digital intervention on the development of algebraic expertise. Computers \& Education, 58(1), 197-208.

Boon, P. (2009). A designer speaks: Designing educational software for 3D geometry. Educational Designer, 1(2). http://www.educationaldesigner.org/ed/volume1/issue2/article7/.

Boon, P. (2004). WELP: Letterrekenen met applets [WELP: Letter arithmetic with applets] Nieuwe Wiskrant, 23(4), 22-27.

Boon, P., \& Drijvers, P. (2006). Chaining operations to get insight in expressions and functions. In M. Bosch (Ed.), Proceedings of the Fourth Congress of the European Society for Research in Mathematics Education (pp. 969-978). Barcelona, Spain: Universitat Ramon Llull.

Doorman, L. M., Drijvers, P., \& Kindt, M. (1994). De grafische rekenmachine in het wiskundeonderwijs [The graphing calculator in mathematics education.] Utrecht, the Netherlands: Utrecht University, Freudenthal Institute.

Doorman, M., Drijvers, P., Gravemeijer, K., Boon, P., \& Reed, H. (2012). Tool use and the development of the function concept: From repeated calculations to functional thinking. International Journal of Science and Mathematics Education, 10(6), 1243-1267. 
Doorman, L.M., Drijvers, P., \& Kindt, M. (1996). Differentiaal- en integraalrekening. Deel 3: Optimaliseren. [Differential and integral calculus. Part 3: Optimisation.] Utrecht, the Netherlands: Utrecht University, Freudenthal Institute.

Doorman, L. M., \& Van der Kooij, H. (1992). Using the computer in space geometry. Zentralblatt für Didaktik der Mathematik, 24(5), 191-196.

Drijvers, P. (2002). Learning mathematics in a computer algebra environment: Obstacles are opportunities. Zentralblatt für Didaktik der Mathematik, 34(5), 221-228.

Drijvers, P. (2003). Learning algebra in a computer algebra environment. Design research on the understanding of the concept of parameter. Doctoral thesis. Utrecht, the Netherlands: CD-Bèta Press. http://dspace.library.uu.nl/handle/1874/886.

Drijvers, P. (2009). Tools and tests: Technology in national final mathematics examinations. In C. Winslow (Ed.), Nordic research on mathematics education. Proceedings from NORMA08 (pp. 225-236). Rotterdam, the Netherlands: Sense.

Drijvers, P. (2016). Evidence for benefit? Reviewing empirical research on the use of digital tools in mathematics education. Paper accepted for ICME13 TSG42.

Drijvers, P., Boon, P., Doorman, M., Bokhove, C., \& Tacoma, S. (2013). Digital design: RME principles for designing online tasks. In C. Margolinas (Ed.), Proceedings of ICMI Study 22 Task design in mathematics education (pp. 55-62). Clermont-Ferrand, France: ICMI.

Drijvers, P., \& Doorman, M. (1996). The graphics calculator in mathematics education. Journal of Mathematical Behavior, 15(4), 425-440.

Drijvers, P., Doorman, M., Kirschner, P., Hoogveld, B., \& Boon, P. (2014). The effect of online tasks for algebra on student achievement in grade 8. Technology, Knowledge and Learning, 19, $1-18$.

Drijvers, P., Godino, J. D., Font, V., \& Trouche, L. (2013). One episode, two lenses: A reflective analysis of student learning with computer algebra from instrumental and onto-semiotic perspectives. Educational Studies in Mathematics, 82(1), 23-49.

Drijvers, P., Kieran, C., \& Mariotti, M. A. (2010). Integrating technology into mathematics education: theoretical perspectives. In C. Hoyles \& J.-B. Lagrange (Eds.), Mathematics education and technology_Rethinking the terrain (pp. 89-132). New York/Berlin: Springer.

Drijvers, P., Tacoma, S., Besamusca, A., Doorman, M., \& Boon, P. (2013). Digital resources inviting changes in mid-adopting teachers' practices and orchestrations. ZDM Mathematics Education, 45(7), 987-1001.

Freudenthal, H. (1973). Mathematics as an educational task. Dordrecht, the Netherlands: Reidel Publishing Company.

Gravemeijer, K. (1999). How emergent models may foster the constitution of formal mathematics. Mathematical Thinking and Learning, 1, 155-177.

Hoyles, C., \& Noss, R. (2003). What can digital technologies take from and bring to research in mathematics education? In A. J. Bishop, M. A. Clements, C. Keitel, J. Kilpatrick, \& F. Leung (Eds.), Second international handbook of mathematics education (Vol. 1, pp. 323-349). Dordrecht, the Netherlands: Kluwer Academic Publishers.

Jupri, A., Drijvers, P., \& Van den Heuvel-Panhuizen, M. (2016). An instrumentation theory view on students' use of an applet for algebraic substitution. International Journal for Technology in Mathematics Teaching, 23(2), 63-80.

Kieran, C., \& Drijvers, P. (2006). The co-emergence of machine techniques, paper-and-pencil techniques, and theoretical reflection: A study of CAS use in secondary school algebra. International Journal of Computers for Mathematical Learning, 11(2), 205-263.

Kindt, M. (1992a). Functie-onderzoek begint met de grafiek I [Investigating a function starts with the graph I]. Euclides, 67(7), 200-204.

Kindt, M. (1992b). Functie-onderzoek begint met de grafiek II [Investigating a function starts with the graph II]. Euclides, 67(8), 227-230.

Kindt, M., \& Boon, P. B. J. (2001). De veelzijdigheid van bollen [Multi-faceted spheres]. Utrecht, the Netherlands: Epsilon. 
Papert, S. (1980). Mindstorms: Children, Computers, and Powerful Ideas. New York, NY: Basic Books.

Sutherland, R., \& Rojano, T. (1993). A spreadsheet approach to solving algebra problems. Journal of Mathematical Behavior, 12(4), 353-383.

Treffers, A. (1987). Three dimensions. A model of goal and theory description in mathematics instruction-The Wiskobas project. Dordrecht, the Netherlands: Reidel.

Trouche, L. (2004). Managing complexity of human/machine interactions in computerized learning environments: Guiding students' command process through instrumental orchestrations. International Journal of Computers for Mathematical Learning, 9, 281-307.

Trouche, L., \& Drijvers, P. (2010). Handheld technology: Flashback into the future. ZDM Mathematics Education, 42(7), 667-681.

Van den Heuvel-Panhuizen, M. (2014). Didactical phenomenology. In S. Lerman (Ed.), Encyclopedia of Mathematics Education (pp. 174-176). Dordrecht, Heidelberg, New York, London: Springer.

Van den Heuvel-Panhuizen, M., \& Drijvers, P. (2014). Realistic Mathematics Education. In S. Lerman (Ed.), Encyclopedia of mathematics education (pp. 521-525). Dordrecht, Heidelberg, New York, London: Springer.

Van Streun, A., \& Van de Giessen, C. (2007). Een vernieuwd statistiekprogramma. Deel 1: Statistiek leren met 'data-analyse' [A reform statistics curriculum. Part 1: Learn statistics through 'data analysis']. Euclides, 82(5), 176-179.

Vonk, G., \& Doorman, M. (2000). Van schrapkaart tot internet. Dertig jaar computers in het onderwijs [From scratch card to internet. Thirty years computers in education]. In F. Goffree, M. van Hoorn, \& B. Zwaneveld, Honderd jaar wiskundeonderwijs (pp. 375-388). Leusden, the Netherlands: Nederlandse Vereniging van Wiskundeleraren.

Open Access This chapter is licensed under the terms of the Creative Commons Attribution 4.0 International License (http://creativecommons.org/licenses/by/4.0/), which permits use, sharing, adaptation, distribution and reproduction in any medium or format, as long as you give appropriate credit to the original author(s) and the source, provide a link to the Creative Commons license and indicate if changes were made.

The images or other third party material in this chapter are included in the chapter's Creative Commons license, unless indicated otherwise in a credit line to the material. If material is not included in the chapter's Creative Commons license and your intended use is not permitted by statutory regulation or exceeds the permitted use, you will need to obtain permission directly from the copyright holder.

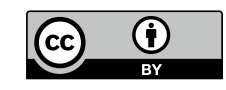

